\title{
OS SABERES TRADICIONAIS E A UTILIZAÇÃO DE PLANTAS MEDICINAIS DURANTE O PERÍODO DE PANDEMIA DA COVID-19
}

\author{
Luís Moreira de Oliveira Filho (D1, Juliana Fernandes da Silva Queiroz (D), \\ Maria Ivanilda de Aguiar ${ }^{\text {iD } 3}$, Elisangela André da Silva Costa (D) 4
}

Resumo: As plantas medicinais são importantes por se constituírem como parte da própria história. E dessa relação homem-natureza, nasceram os conhecimentos e os saberes tradicionais, a partir dos quais se fundam cultura e experiências na utilização de plantas medicinais. Nesse contexto, este trabalho teve como objetivo analisar como os saberes etnobotânicos, especificamente das plantas medicinais têm contribuído para o cuidado com a saúde das famílias de alguns estudantes em realidades divergentes, nesse período de pandemia da Covid-19. Assim, realizou-se uma análise comparativa entre duas escolas, uma escola localizada no "campo", zona rural de Madalena, Ceará, Brasil, a escola EEM João dos Santos de Oliveira e a outra, escola localizada na região metropolitana de Fortaleza, em Pacajus, Ceará, Brasil, denominada EEM Dione Maria Bezerra Pessoa. Quanto aos procedimentos metodológicos, a pesquisa partiu de um questionário semiestruturado com a finalidade da coleta e produção de dados, utilizando-se das abordagens quantitativa e qualitativa. Os sujeitos da pesquisa foram 60 estudantes, 30 de cada escola. 0 estudo revelou que a localização e etnosaberes adquiridos pelos estudantes do campo e na região metropolitana, não apresentam divergências significativas, considerando a variação de convívio social e cultural.

Palavras-chave: Coronavírus; Etnosaberes; Remédios caseiros.

\section{TRADITIONAL KNOWLEDGE: HOW STUDENT FAMILIES USE MEDICINAL PLANTS IN THE COVID-19 PANDEMIC PERIOD}

\begin{abstract}
Medicinal plants are important because they are part of the history of humanity. And from this man-nature relationship, traditional knowledge and knowledge were born, from which culture and experiences in the use of medicinal plants are based. In this context, this study aimed to analyze how

\footnotetext{
${ }^{1}$ Mestrando em Sociobiodiversidade e Tecnologias Sustentáveis pela Universidade da Integração Internacional da Lusofonia Afro-Brasileira (UNILAB), Redenção-CE. Professor da Rede Pública Estadual do Ceará. Email: professorluismoreira@gmail.com.

${ }^{2}$ Mestranda em Sociobiodiversidade e Tecnologias Sustentáveis pela Universidade da Integração Internacional da Lusofonia Afro-Brasileira (UNILAB). Professora da Rede Pública Estadual do Ceará. Email: 3jhulyfernandes@gmail.com.

${ }^{3}$ Doutora em Ecologia e Recursos Naturais pela Universidade Federal do Ceará (UFC). Professora no Mestrado Acadêmico em Sociobiodiversidade e Tecnologias Sustentáveis da UNILAB, Redenção-CE, Brasil. E-mail: ivanilda@unilab.edu.br.

${ }^{4}$ Doutora em Educação pela Universidade Federal do Ceará (UFC). Professora Adjunta da Universidade da Integração Internacional da Lusofonia Afro-Brasileira (UNILAB). E-mail: elisangelaandre@unilab.edu.br.
} 
ethnobotanical knowledge, specifically medicinal plants, has contributed to the health care of some students' families in divergent realities, during this period of the Covid-19 pandemic. Thus, a comparative analysis was carried out between two schools, one school located in the "field", rural area of Madalena, Ceará, Brazil, the EEM João dos Santos de Oliveira school and the other school located in the metropolitan region of Fortaleza, in Pacajus, Ceará, Brazil, named EEM Dione Maria Bezerra Pessoa. As for the methodological procedures, the research started with a semi-structured questionnaire with the purpose of collecting and producing data, using quantitative and qualitative approaches. The research subjects were 60 students, 30 from each school. The study revealed that the location and ethnosabers acquired by rural students and in the metropolitan region do not present significant differences, considering the variation in social and cultural interaction.

Keywords: Coronaviruses; Ethnosabers; home remedies

\section{Introdução}

A partir da Revolução Cognitiva há 70 mil anos, o homem, Homo sapiens, inventou estruturas elaboradas, chamadas de culturas, tendo em vista que não se buscavam apenas alimentos e materiais na natureza, mas principalmente conhecimentos sobre os segredos da natureza e das plantas que se coletava (HARARI, 2020).

No livro "A Vida Secreta das Plantas" os autores Tompkins e Bird (1986) discorrem que as plantas, envolvidas no milagre e na doçura da fotossíntese, são essenciais para a vida de todo o planeta. Através das plantas, os seres humanos podem se alimentar, beber, mas também utilizar de algumas espécies botânicas com propriedades medicinais para mantê-los vivos e saudáveis se tomados de forma correta.

Krenak (2020) chama a atenção para este momento de pandemia em visão dualista para o ser humano: reafirma-se e se encontra em sua humanidade enquanto ser social e solidário, ou reforça ainda mais sua visão antropocêntrica, ou seja, como discorre o autor, o homem como "sal da terra" que nega a pluralidade das formas de vida, da diversidade, saberes, existências e hábitos. Para Krenak (2020, p.13), "para se combater o novo coronavírus primeiro é preciso ter cuidado e depois coragem".

Nesse sentido, vale ressaltar que o novo Coronavírus, de nome SARS-CoV2, é o patógeno causador da doença Covid 19, cujo epicentro pandêmico teve origem na China no início de 2020, embora ainda seja motivo de estudos e pesquisa o local exato em que emerge esse novo coronavírus que mudou a vida das pessoas, principalmente no trabalho, obrigando-as ao isolamento social e formas de prevenção e cuidado com a saúde. E no momento, os números de infectados e mortos só têm aumentado no mundo e no Brasil, motivando muitas pessoas a buscarem formas de trabalho e fortalecimento do sistema imunológico e também plantas medicinais e suas propriedades biológicas para tratar de alguns sintomas causados pelo novo coronavírus, conforme explica Cavalcanti (2020). 
Nessa linha de pensamento, as plantas medicinais fazem parte da história da própria existência humana e são aquelas que segundo Brandão e Almeida (2011) são utilizadas, por exemplo, para fazer chás. Para estas autoras, as ações farmacológicas das plantas medicinais são possibilitadas por substâncias químicas chamadas de "princípios ativos" e conhecidas por fitofármacos.

Sobre saberes, Freire (1996) observa que a escola, como espaço primordial do aprendizado do conhecimento historicamente acumulado, deve considerar o que os estudantes, principalmente das classes populares, trazem conhecimentos de suas comunidades, ou seja, conhecimentos socialmente construídos na prática comunitária, discutindo a relação desses saberes com os conteúdos. Pergunta o mestre: "Por que não estabelecer uma necessária "intimidade" entre os saberes curriculares fundamentais aos alunos e a experiência social que eles têm como indivíduos"? (FREIRE, 1996, p. 14).

Nesse sentido, faz-se importante questionar: como as famílias de estudantes residentes na zona rural e urbana fazem usos de plantas medicinais neste período de pandemia da Covid 19? Quais as plantas mais utilizadas? Existe alguma relação do uso entre as plantas medicinais sobre o amparo das diferentes realidades, que traga a luz a uma possível forma de tratamento da doença causada pelo vírus vigente, que ainda não foi comprovado cientificamente? Dessa forma, o presente estudo objetivou analisar como os saberes etnobotânicos, especificamente das plantas medicinais têm contribuído para o cuidado com a saúde das famílias de alguns estudantes em realidades divergentes, nesse período de pandemia da Covid-19.

\section{Material e métodos}

A pesquisa foi desenvolvida em duas escolas localizadas em regiões do Ceará, uma escola do campo que é a EEM João dos Santos de Oliveira, figura 1, Mesorregião dos Sertões Cearenses, mais especificamente situada na Microrregião do Sertão de Quixeramobim, Ceará, Brasil.

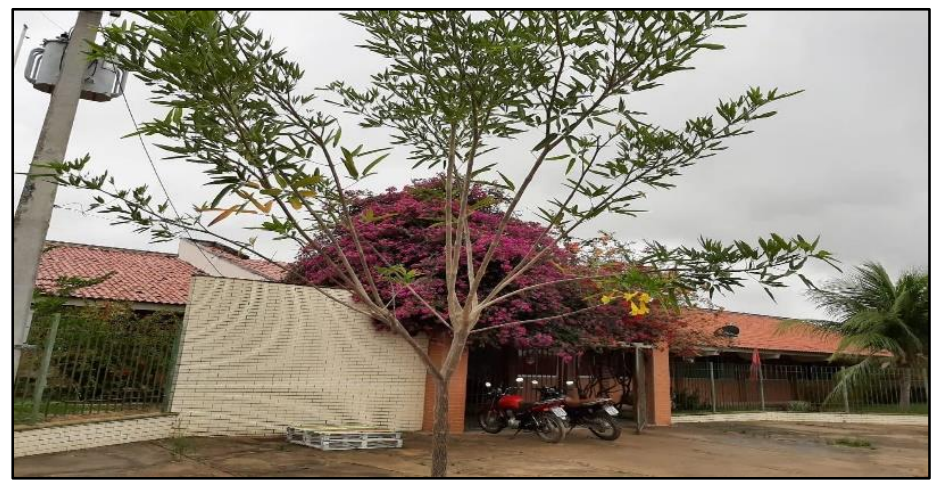

Figura 1: EEM João dos Santos de Oliveira.

Fonte: Gestores da Escola.

A escola do campo é a Escola de Ensino Médio (EEM) João dos Santos de Oliveira, que está localizada em área de assentamento rural, na cidade de 
Madalena, Ceará. A instituição oferece ensino médio regular para 120 alunos, atualmente, sendo 43 alunos na $1^{a}$ série, 37 alunos na $2^{a}$ série e 40 na $3^{a}$ série.

E a outra escola está localizada na Mesorregião Metropolitana de Fortaleza, Microrregião de Pacajus, Ceará, Brasil, denominada EEM Dione Maria Bezerra Pessoa, figura 2, está instalada na cidade de Pacajus, Ceará. A instituição oferece ensino médio regular, atendendo, atualmente, a um total de 834 estudantes, sendo 265 alunos na $1^{\text {a }}$ série, 235 alunos na $2^{a}$ série e 334 alunos na $3^{a}$ série.

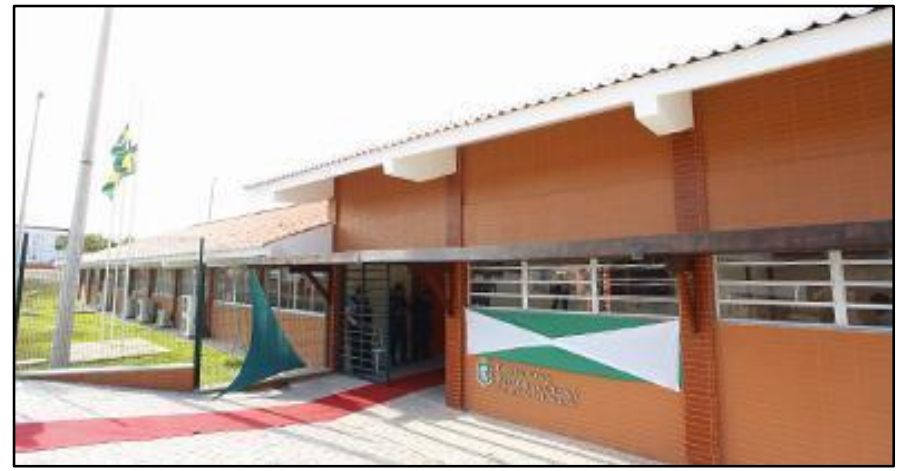

Figura 2: EEM Dione Maria Bezerra Pessoa.

Fonte: Site Governo Estadual.

Para realização do trabalho foi iniciada uma parceria com a direção de cada escola para explanação do objetivo da pesquisa e solicitação de participação voluntária dos alunos para responder ao questionário semiestruturado em formulário do Google Forms, deixando esclarecido para as respectivas direções das escolas e alunos as informações levantadas irão colaborar na elaboração de uma pesquisa a ser publicada posteriormente; que o objetivo da referida pesquisa será analisar como os saberes etnobotânicos, especificamente das plantas medicinais têm contribuído para o cuidado com a saúde das famílias de alguns estudantes em realidades divergentes, nesse período de pandemia da Covid-19; que o preenchimento do questionário não é obrigatório sendo de livre concordância da direção das referidas escolas; que os alunos não serão identificados e que, enquanto sujeitos da pesquisa, poderão deixar de participar durante a coleta de dados.

Após explicar o objetivo da pesquisa à metodologia e com a concordância da direção das duas escolas foi iniciada a coleta de dados através do questionário semiestruturado com perguntas abertas e fechadas, utilizando-se da ferramenta Google Forms. Dessa forma, os estudantes tiveram a oportunidade de participar dessa pesquisa sobre trato inicial do uso de plantas medicinais nesse momento de pandemia,

Foram realizadas onze perguntas, sendo as indagações fechadas no total de oito perguntas através de questionário, contemplando investigações relacionadas à idade, localização geográfica, sexo, escola a que pertence, qual finalidade do uso das plantas medicinais, com quem adquiriram o conhecimento, frequência de uso das plantas medicinais na pandemia e finalidade do uso e tratamentos de alguns sintomas da Covid-19, como problemas digestivos, diarreia, náusea e vômitos fadiga, dor de cabeça, febre conforme discorre 
Cavalcanti (2020) em sua pesquisa sobre plantas medicinais e possíveis benefícios no enfrentamento da Covid-19.

Já as perguntas abertas foram três que tiveram como objetivo analisar o conhecimento sobre plantas medicinais usadas pelas famílias tradicionalmente para tratamento de sintomas de doenças; quais plantas eram usadas para tratar ou prevenir a Covid-19 e relato de um episódio de uso emergencial da planta medicinal na pandemia para primeiros tratamentos de sintomas do coronavírus. Vale, também, ressaltar que as perguntas lançadas em questionário foram propostas em uso voluntário, apresentando-se de forma objetiva e clara, uma vez que se obteve um número de respostas expressivas e que oportunizaram realizar a análise dos dados da pesquisa empírica.

A coleta de dados foi realizada entre março e maio de 2021, junto a 60 alunos das duas escolas, sendo 30 alunos de cada instituição, 10 de cada série do ensino médio, que se submeteram de forma espontânea à pesquisa. A análise foi feita pelos relatórios fornecidos do Google Forms paralelo à planilha de respostas gerada pela planilha Excel. Primeiramente foi feita a separação dos dados por escola, a seguir criados os gráficos pelo Excel, e tabelas pelo Word, com os dados fornecidos, alimentando assim uma abordagem quantitativa dos resultados.

Após separadas, as respostas abertas dos estudantes foram submetidas a uma análise qualitativa, pela ordem de resposta e por escola, seguindo o exemplo: E2- Escola campo, que pode ser lido como, segundo estudante a responder o questionário pertencente a escola do campo (EEM João dos Santos Oliveira). Para a escola EEM Dione Maria Bezerra Pessoa foi utilizado o formato inicial (Letra E, e ordem) acrescido de "Escola metropolitana". Toda a apresentação dos dados foi realizada de forma paralela e comparativa, abordando os contributos dos estudantes das duas escolas, em diferentes realidades.

\section{Resultados e discussões}

A idade dos estudantes participantes variou de 14 a 23 anos, sendo $60 \%$ do sexo feminino, $38,3 \%$ do sexo masculino e $1,7 \%$ não declaram. Desses participantes, os da escola EEM João dos Santos Oliveira (Escola do Campo), declararam $100 \%$ residência na zona rural (área de assentamento) e os da EEM Dione Maria Bezerra Pessoa (Escola Metropolitana) 93,3\% residem em zona urbana e $6,7 \%$ na zona rural.

A maioria dos estudantes afirmou ter conhecimentos prévios relacionados às plantas medicinais, sendo que o percentual foi maior para os estudantes da escola do campo (93,3\%), em relação ao da escola Metropolitana $(83,3 \%)$. Porém uma parcela dos estudantes, que variou de 3,3\% a 16,7\%, para as escolas do campo e metropolitana, respectivamente, não têm certeza quanto ao conhecimento relativo a plantas medicinais; enquanto $3,3 \%$ dos estudantes da escola do campo afirmaram não ter estes conhecimentos.

Estes resultados corroboram com os estudos de Kffuri (2011) ao apontar a importância das plantas medicinais a partir de dados da Organização Mundial de Saúde (OMS), em que entre $65 \%$ - 80\% da população mundial, de países em 
desenvolvimento, depende das propriedades medicinais de plantas para o cuidado e atenção primária, revelando, dessa forma, uma estreita relação entre homem plantas, integrando biodiversidade e sociobiodiversidade. Várias plantas medicinais foram citadas pelos estudantes, mas hortelã (Mentha spicata), boldo (Peumus boldus) e cidreira (Melissa officinalis) tiveram mais destaques por membros das duas escolas para uso de atenção primária como tratamentos para diarreia, vômitos, dor de cabeça e febre, conforme referências no quadro 1 .

Não obstante, essa situação caracteriza uma cultura etnomedicina utilizada pelos povos tradicionais e que certamente é transmitida de forma oral entre as famílias ao longo de suas histórias, tendo em vista, segundo Alho (2002, p.155 apud Farnsworth, 1988) que "80\% dos habitantes de países em desenvolvimento dependem da medicina tradicional para suprir suas necessidades básicas de saúde, e $85 \%$ dos medicamentos produzidos pela medicina tradicional envolve o uso de extratos de plantas, portanto remédios originários da natureza".

Segundo Grana (2021) o consumo de remédios caseiros cresceu durante a pandemia do Covid-19, principalmente em regiões como o Amazonas que teve grande surto com nova variante do novo coronavírus. Segundo a autora, os amazonenses passaram a consumir remédios caseiros em profusão para prevenir e até mesmo tratar sintomas dessa enfermidade, entre estes remédios têm destaque: "Limão (Citrus limonum) jambu, (Acmella oleracea) mel de abelhas, mastruz (Dysphania ambrosioides) e andiroba (Carapa guianensis). Estes dados também se reverberam nessa pesquisa que também revelou o consumo habitual das famílias em remédios caseiros a partir de plantas medicinais, antes e durante a pandemia. Para Grana (2021) a "Covid-19 reforçou o debate sobre a produção de medicamentos fitoterápicos para o enfrentamento do novo coronavírus e de outras doenças".

Importa considerar que não há nenhuma pesquisa científica que aponte alguma planta medicinal que possa curar o novo coronavírus, mas matéria do 0 Estado de Minas, de vinte de maio de 2020, mostra que povos tradicionais como os indígenas da Amazônia estão utilizando etnosaberes como ervas medicinais para tratamentos de sintomas da doença os quais os seus antepassados transmitiram de forma oral. Também segundo Pires (2020) pesquisa internacional avalia uso de fitoterápicos no trabalho contra a Covid-19. E que importa observar que não há cura para a Covid-19, mas o artigo de Pires (2020) sobre plantas medicinais mais utilizadas no tratamento de três sintomas iniciais do Covid-19 - tosse, gripe, resfriado se reverbera nesse trabalho com estudantes de duas escolas e conforme se apresenta com as plantas mais utilizadas por suas famílias.

Um aspecto importante a considerar nessa análise é constatar como é rica em plantas medicinais a biodiversidade brasileira que segundo Alho (2011, p.152) sua "importância para o bem-estar e a saúde humana só ganhou maior destaque quando o processo de perda da diversidade biológica alertou para a necessidade da conservação e do uso racional dos recursos vivos". No entanto, também é importante considerar o que observa Diegues et at., (1999, p. 30) quando discorre sobre o conceito de "conhecimento tradicional como o conjunto de saberes e saber-fazer a respeito do mundo natural, sobrenatural, transmitido 
oralmente de geração em geração". Segundo o autor, para muitas das sociedades "há interligação orgânica entre o mundo natural, o sobrenatural e a organização social". (DIEGUES et at.,1999, p. 30).

Nessa linha de pensamento em análise, a partir dos resultados coletados, percebe-se, também, essa integração das famílias com os saberes a respeito das plantas medicinais, de acordo com os dados coletados conforme quadro 1.

QUADRO 1: Plantas medicinais que os estudantes e/ou seus familiares já usaram ou usam.

\begin{tabular}{|c|c|}
\hline $\begin{array}{l}\text { EEM João Oliveira dos Santos } \\
\text { (Escola do Campo) }\end{array}$ & $\begin{array}{l}\text { EEM Dione Maria Bezerra Pessoa } \\
\text { (Escola Metropolitana) }\end{array}$ \\
\hline $\begin{array}{c}\text { Nome popular (Nome } \\
\text { científico) / número de citações }\end{array}$ & $\begin{array}{l}\text { Nome popular (Nome científico) } \\
\text { /número de citações }\end{array}$ \\
\hline 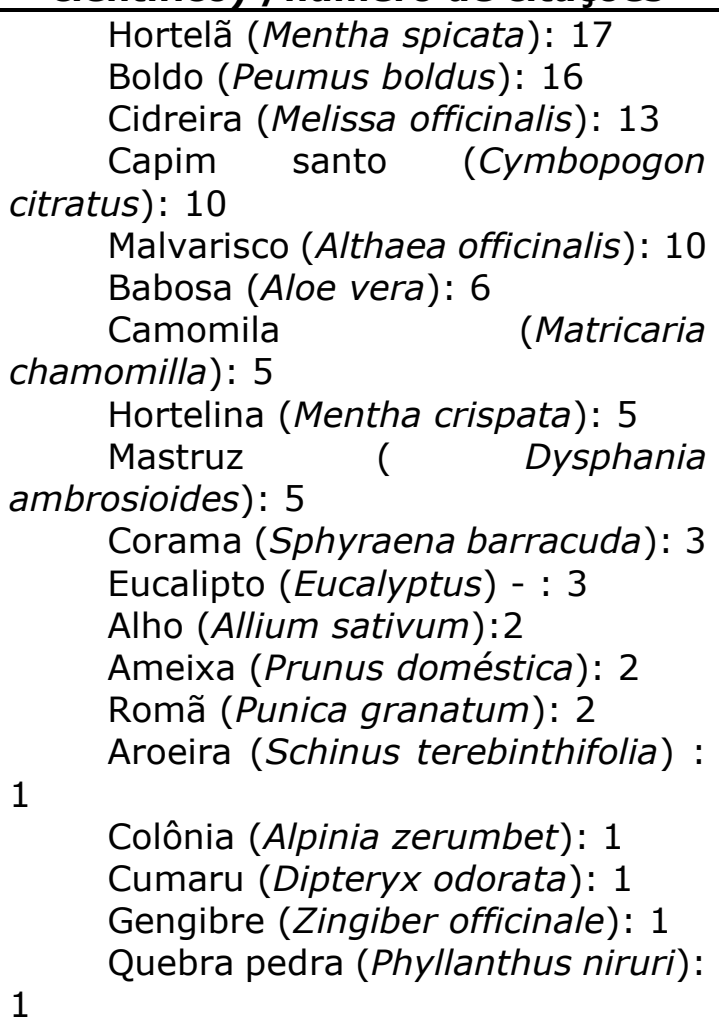 & $\begin{array}{l}\text { Boldo (Peumus boldus) - } 14 \\
\text { Cidreira (Melissa officinalis) - } 10 \\
\text { Camomila (Matricaria chamomilla) - } 8 \\
\text { Hortelã (Mentha spicata)- } 8 \\
\text { Capim santo (Cymbopogon citratus) - } 7 \\
\text { Babosa (Aloe vera) - } 5 \\
\text { Eucalipto (Eucalyptus) - } 5 \\
\text { Mastruz (Dysphania ambrosioides) - } 4 \\
\text { Corama (Bryophyllum pinnata) - } 2 \\
\text { Erva doce (Pimpinella anisum) - } 2 \\
\text { Folha da goiabeira (Psidium guajava) - } 2 \\
\text { Alfavaca (Ocimum gratissimum) - } 1 \\
\text { Anis-estrelado (Illicium verum)- } 1 \\
\text { Canabidiol (canabidiol) - } 1 \\
\text { Canela (Cinnamomum verum) - } 1 \\
\text { Coentro (Coriandrum sativum) - } 1 \\
\text { Endro ( Aneethun graveolens) - } 1 \\
\text { Linhaça (Linum usitatissimum) - } 1 \\
\text { Louro (Laurus nobilis) - } 1 \\
\text { Guaco (Mikania glomerata Spreng) - } 1 \\
\text { Malvarisco (Althaea officinalis) - } 1 \\
\text { Quebra pedra (Phyllanthus niruri) - } 1\end{array}$ \\
\hline
\end{tabular}

Fonte: produzido pelos (as) pesquisadores (as) a partir dos formulários eletrônicos.

Vale ressaltar que estes dados coletados e analisados, revelaram que moradores da região metropolitana, apesar de apresentarem uma maior diversidade nas citações das plantas medicinais, não compreendem bem o que sejam plantas medicinais e suas finalidades e propriedades terapêuticas, uma vez que citaram coentro, canela e linhaça que são mais utilizadas como complementos de alimentos do que como plantas medicinais. Concordando com Cavalcanti (2020, p.11), as plantas medicinais são, "de acordo com a Agência Nacional de Vigilância Sanitária (ANVISA), todos os vegetais, ou parte destes que apresentam ação terapêutica".

Segundo Pereira et al. (2020), a linhaça, como alimento funcional, pertence à classe dos alimentos intitulados como nutracêuticos porque, segundo os autores contém "propriedades funcionais sobre células, tecidos e órgãos e são 
alimentos ou ingredientes que produzem efeitos benéficos à saúde, além de suas funções nutricionais básicas" (PEREIRA et al., 2020, p. 196).

Também vale destacar que a canela, citada no quadro 1 , mas comumente vendida em supermercados e mercadinhos como Canela da China é da espécie cinnamomum cassia, é sim uma planta medicinal, mas muito utilizada na culinária nordestina no leite, mingau, canjica, etc., no entanto, sua propriedade medicinal é reconhecida em pesquisas e que segundo Silva et al. (2020, p.7) ) às "substâncias biológicas ativas presentes regulam o açúcar no sangue, por possuir propriedades miméticas à insulina, que aumenta a captura de glicose". Para os referidos autores, a canela pode ser uma alternativa para terapia.

Por outro lado, Cavalcanti (2020), aponta outras espécies de canela como: a Cinamomum zeylanicum que combate sintomas de diabetes e também atua no combate à asma; a Canela de Veado - Helietta apiculata - que combate tosses; Canela do Ceilão - Cinamomum verum - que atua no combate a tosses. Dessa forma, a diversidade de plantas mostradas representa saberes culturais diversos transmitidos entre famílias que segundo Castro e Figueredo (2019, p. 68) "as pesquisas com plantas medicinais continuam sendo realizadas e a inclusão desta prática nas unidades de atenção primária da saúde consideram o saber popular sobre os remédios caseiros". E o desafio para as ciências, segundo os autores, é comprovar, através de pesquisas científicas, a eficácia e toxicidade destes saberes que atravessam gerações de forma oral.

Quanto à finalidade de uso das plantas medicinais conforme quadro 2, a maioria das respostas dos alunos de ambas as escolas se concentrou em "tratamento de doenças", mas seguido de "prevenção de doenças". Dessa forma, importa considerar a preocupação nesse momento das ciências e seus pesquisadores sobre plantas que podem reduzir os sintomas da Covid-19 conforme, por exemplo, cartilha produzida pelo Laboratório de Farmacognosia e Homeopatia da Universidade Federal de Minas Gerais em que busca explicar a importância das plantas medicinais e seus derivados terapêuticos que são utilizados pelas populações brasileiras nos cuidados primários à saúde. Destacam os pesquisadores que as "plantas medicinais podem ser muito úteis para combater os males ocasionados pelo isolamento social como depressão, ansiedade e insônia e que podem atuar no sistema respiratório e imunológico" (JESUS et al., 2020). 
QUADRO 2: Indicação da finalidade do uso dessa planta medicinal na residência dos estudantes.

\begin{tabular}{|c|c|}
\hline $\begin{array}{c}\text { EEM João Oliveira dos Santos } \\
\text { (Escola do Campo) }\end{array}$ & $\begin{array}{c}\text { EEM Dione Maria Bezerra Pessoa } \\
\text { (Escola Metropolitana) }\end{array}$ \\
\hline $\begin{array}{l}\text { Finalidade / número de } \\
\text { citações }\end{array}$ & Finalidade / Número de citações \\
\hline $\begin{array}{c}\text { Prevenção de doenças: } 17 \\
\text { Tratamento de doenças: } 24 \\
\text { Uso alimentar: } 4 \\
\text { Outros: } 4\end{array}$ & $\begin{array}{c}\text { Prevenção de doenças - } 13 \\
\text { Tratamento de doenças - } 27 \\
\text { Uso alimentar - } 5 \\
\text { Outros - 5 }\end{array}$ \\
\hline
\end{tabular}

Fonte: produzido pelos (as) pesquisadores (as) a partir dos formulários eletrônicos.

Quando os estudantes atribuem à gênese dos conhecimentos adquiridos, mostram que os saberes tradicionais se dão através de gerações dentro do ambiente familiar. Como afirma Capra (2002) que nenhum ser vivo pode viver de forma isolada porque há um tecido que une a todos pela interdependência e interações necessárias à vida. Há, assim, segundo este pesquisador uma conexão oculta, porque a relação entre animais, vegetais e microrganismos regula toda a biosfera para o equilíbrio e manutenção das condições propícias à vida, reverberando-se na importância da etnobotânica que é definida como:

O estudo das interações e o relacionamento entre plantas e seres humanos no tempo e no espaço, incluindo usos, conhecimentos, crenças, sistemas de manejo, sistemas de classificação e linguagem das culturas tradicionais e modernas e sua associação com o ecossistema (KFFURI, 2011, p. 5).

QUADRO 3: Com quem os estudantes adquiriram conhecimento sobre plantas medicinais.

\begin{tabular}{|c|c|}
\hline $\begin{array}{c}\text { EEM João Oliveira dos Santos } \\
\text { (Escola do Campo) }\end{array}$ & $\begin{array}{c}\text { EEM Dione Maria Bezerra Pessoa } \\
\text { (Escola Metropolitana) }\end{array}$ \\
\hline Conhecimento / número de & Conhecimento / Número de citações \\
citações & Família - 29 \\
\hline Família: 28 & Escola -4 \\
Escola: 7 & Vizinhos -5 \\
Vizinhos: 1 & Redes sociais - 7 \\
Redes sociais: 4 & Outros - 1 \\
\hline Outros: 0 & Cus
\end{tabular}

Fonte: produzido pelos (as) pesquisadores (as) a partir dos formulários eletrônicos.

Expõe-se, ainda, pela análise dos Quadros 1 e 3, que como nas regiões metropolitanas ocorre imigração de indivíduos, registra-se também a presença de saberes tradicionais distintos. Observou-se no Quadro 1 a concentração das plantas citadas em maiores quantidades e menos diversidades na região da escola do campo. Este aspecto diverge do ocorrido na escola metropolitana, podendo estar relacionado às origens adquiridas dos saberes tradicionais sobre plantas medicinais (Quadro 3). Nessa linha de pensamento, Diegues (2019) escreve que os povos tradicionais além de conviverem com a biodiversidade, 
nomeiam, classificam as espécies segundo suas categorias e nomes. E que por isso, para o autor, deve-se falar em "etnobiodiversidade que é a riqueza da natureza da qual participam os humanos, nomeando-a, classificando-a, domesticando-a" (DIEGUES, 2019, p. 120). Conclui ainda o autor:

[...] a biodiversidade pertence tanto ao domínio do natural quanto do cultural, mas é a cultura enquanto conhecimento que permite às populações tradicionais entendê-la, representá-la mentalmente, manuseá-la, além de retirar espécies, colocar outras e enriquecendo assim a própria sociobiodiversidade ou etnobiodiversidade (DIEGUES, 2019, p. 120).

Evidenciando agora essa pesquisa na atual situação vigente, causada pela Covid-19, têm-se mostrado altas taxas de letalidade, afetando principalmente indivíduos com diabetes, comorbidades diversas, idosos entre outros (BRAGA, 2021). Além do mais, estudos confirmam que há um auxílio de muitas plantas, empregadas como extratos brutos ou seus ingredientes ativos, contra os vírus respiratórios (KHAN et al., 2021). Por outro lado, pesquisas como dos pesquisadores Mafra, Lasmar e Rivas (2020, p.5) apontam que "remédios caseiros foram utilizados como alternativas preventiva e terapêutica ao Covid19, além de ser um hábito que antecede a pandemia e que provém das famílias a indicação destes remédios". Além do mais as populações desfavorecidas economicamente não têm $o$ acesso aos remédios produzidos pela rica e dominante indústria farmacêutica, o que carece da "etnobotânica busca estudar a relação homem-planta e o resgate de saberes tradicionais difundidos entre as gerações" (CARVALHO et al., 2019).

Em busca de investigar se o uso dessas plantas no tratamento e atenção primária da Covid-19, primeiramente questionaram-se como os estudantes observam a frequência do uso das plantas medicinais em diferentes esferas, podendo citar mais de uma resposta. Assim, na escola do campo obtiveram-se os seguintes resultados quantitativos de citações entre parênteses: nenhuma (0), familiaris (14), vizinhos (6), sua residência (18) e outros (1); na escola localizada na região metropolitana os resultados foram e quantidade de citações entre parênteses: nenhuma (4), familiares (20), vizinhos (3), sua residência (12) e outros (2).

Ao investigar, a priori, se os estudantes têm feito o uso frequente das plantas medicinais neste período de pandemia da Covid-19, os resultados apontam que mais de $70 \%$ dos sujeitos usaram plantas medicinais no período de pandemia (Figura 3 - (A) e 1 (B)). 


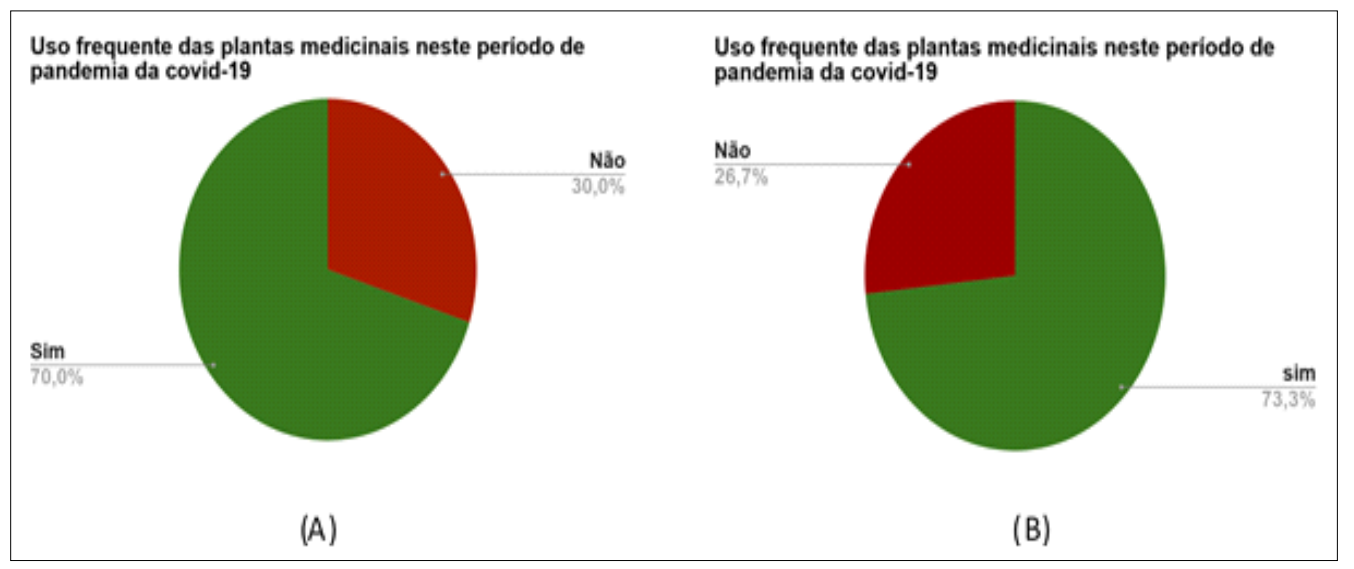

Figura 3: EEM João Oliveira dos Santos (A) e EEM Dione Maria Bezerra Pessoa (B). Fonte: produzido pelos (as) pesquisadores (as) a partir dos formulários eletrônicos.

A figura 3 (A-B) ilustra que independentemente das localizações e realidades vivenciadas ocorre uma preocupação com a saúde, fazendo o uso das plantas medicinais. Braga (2021) destaca que a pandemia causada pela doença Covid-19, a população tem se preocupado com a imunidade, por causa da letalidade que a doença pode causar. Neste sentido, os estudantes revelaram preocupação do uso dessas plantas medicinais para aumentar a imunidade e/ou para auxiliar na imunidade e redução dos sintomas que foram positivas nas duas realidades. Outros apontam para a importância da prevenção e apenas um aluno aponta a possibilidade de cura, o que é um indicador importante do conhecimento dos alunos de que ainda não há cura para essa doença e que a vacina é o melhor caminho com cuidados preventivos para vencer o Covid-19.

Importa considerar que a questão da possibilidade de cura foi colocada para perceber o nível de consciência dos alunos para essa situação em momento em que muitas informações errôneas são transmitidas em redes sociais como atestam Neto et al. (2020) em suas pesquisas sobre a fake news em relação à pandemia do Covid-19 que a "disseminação de notícias diversas acontece em paralelo, gerando prejuízo que causa a informação equivocada em saúde para a população". 
QUADRO 4: Finalidade do uso das plantas medicinais para auxiliar no combate a Covid-19.

\begin{tabular}{|c|c|}
\hline $\begin{array}{l}\text { EEM João Oliveira dos Santos } \\
\text { (Escola do Campo) }\end{array}$ & $\begin{array}{c}\text { EEM Dione Maria Bezerra Pessoa } \\
\text { (Escola do Metropolitana) }\end{array}$ \\
\hline $\begin{array}{l}\text { Finalidade / número de } \\
\text { citações }\end{array}$ & Finalidade/ Número de citações \\
\hline $\begin{array}{c}\text { Aumentando a imunidade - } \\
18 \\
\text { Prevenindo contra o contágio } \\
-6 \\
\text { Curando - } 1 \\
\text { Auxiliando a cura, juntamente } \\
\text { com remédios - } 9 \\
\text { Não sei responder - } 7 \\
\text { Outras - } 2\end{array}$ & $\begin{array}{c}\text { Aumentando a imunidade - } 28 \\
\text { Prevenindo contra o contágio- } 4 \\
\text { Curando - } 0 \\
\text { Auxiliando a cura, juntamente com } \\
\text { remédios - } 15 \\
\text { Não sei responder - } 2 \\
\text { Outras - } 0\end{array}$ \\
\hline
\end{tabular}

Fonte: produzido pelos (as) pesquisadores (as) a partir dos formulários eletrônicos.

As plantas que foram utilizadas como atenção primária e para tratamento e/ou redução à Covid-19 podem ser observadas no Quadro 5. É interessante ressaltar que o boldo, citado como de uso geral pelas famílias, também aparece com elevado número de citações em relação ao tratamento da Covid-19 na escola do campo.

\section{Quadro 5: Planta Medicinal (nome científico) usada para prevenir ou tratar sintomas da Covid-19.}

\begin{tabular}{|c|c|}
\hline $\begin{array}{c}\text { EEM João Oliveira dos Santos } \\
\text { (Escola Campo) }\end{array}$ & $\begin{array}{c}\text { EEM Dione Maria Bezerra Pessoa } \\
\text { (Escola Metropolitana) }\end{array}$ \\
\hline Finalidade / número de \\
citações & Finalidade/ Número de citações \\
\hline Boldo (Peumus boldus): 10 & Cidreira (Melissa officinalis) -4 \\
Limão (Citrus $\times$ limon): 2 & Mastruz (Dysphania ambrosioides) - \\
Mastruz (Dysphania & Boldo (Peumus boldus) -3 \\
ambrosioides): 2 & Hortelã (Mentha spicata) -2 \\
Alho (Allium sativum): 1 & Alho (Allium sativum) -1 \\
Andiroba (Carapa & Capim santo (Cymbopogon citratus) -1 \\
guianensis): 1 & Erva doce (Pimpinella anisum) -1 \\
Capim-limão (Cymbopogon & Eucalipto (Eucalyptus) -1 \\
citratus): 1 & Limão (Citrus X limon) -1 \\
Capim-santo (Cymbopogon & \\
citratus): 1 & Guaco (Mikania glomerata Spreng) -1 \\
Cumaru (Dipteryx odorata): 1 & \\
Hortelã (Mentha spicata): 1 & \\
Hortelina (Mentha crispata): & \\
1 & \\
Malvarisco (Althaea & \\
officinalis): 1 & \\
Romã (Punica granatum): 1 & \\
\hline
\end{tabular}

Fonte: produzido pelos (as) pesquisadores (as) a partir dos formulários eletrônicos.

Observou-se que não existe uma planta medicinal de uso em comum, ou seja, específica para Covid-19 frente às duas realidades sociais mesmo porque Perspectivas em Diálogo, Naviraí, v. 8, n. 18, p. 276-292, jul/dez. 2021. 
as ciências ainda buscam evidências de remédio natural para a Covid-10 como aponta matéria de Germano (2020) de que "pesquisadores da Universidade Federal da Paraíba estão buscando evidências de remédio natural para Covid19, doença causada pelo novo coronavírus (SARS-CoV)".

Além do mais, essa análise colabora com os estudos de Cavalcanti (2020), em que aponta que muitas plantas medicinais têm comprovação científica, auxiliando no restabelecimento da imunidade e outras aplicações como combater dores, diminuir estresses, além de outras propriedades antimicrobiana e anti-inflamatória, porém ainda não se tem comprovação quanto à eficácia dessas plantas contra a Covid-19.

Reflete-se que não existe um estudo comprovado sobre a planta medicinal que seja eficaz ao combate ao vírus da Covid-19, por outro lado percebe-se que pela diversidade citada, essas plantas têm sido utilizadas para o tratamento e/ou prevenção de sintomas como foi mostrado no Quadro 4, causando assim menos efeitos colaterais ao organismo, o que colabora nessa análise sobre a importância dos saberes e também do conhecimento científico.

Nesse sentido, Diegues (2008) destaca o confronto de dois saberes: de um lado o saber tradicional que é acúmulo de conhecimento das populações tradicionais sobre a natureza, de outro saber científico que além de desconsiderar o conhecimento tradicional acumulado, arvora-se como detentor de conhecimento em um país não só rico em biodiversidade, principalmente de plantas medicinais, mas também de sociobiodiversidade. Como afirma Diegues (2019, p. 122) "ainda que a ciência moderna e a tradicional sejam duas formas de saberes, a relação entre ambas continua sendo pouco estudada". O que vigora, segundo o autor, é a ciência reducionista que discrimina os saberes tradicionais, mas que precisam ser superados.

Por fim, serão apresentadas as discussões qualitativas em relação ao relato de um episódio ocorrido na memória dos estudantes em que ocorreu o uso da planta medicinal em caráter emergencial, por não ser possível o uso de um remédio farmacológico, que podem ser visualizados nos seguintes depoimentos: alho quando faltam medicamentos para pressão arterial alta. Importa considerar outros depoimentos:

Boldo para dor de barriga. Hortelã para nariz entupido (E3-Escola do campo); "Minha mãe bebeu um remédio caseiro com as plantas medicinais para aumentar a imunidade dela, pois ela estava fraca" (E9Escola do Campo); Dor de garganta (tosse seca, sintoma da Covid-19) Fazer gargarejo com chá de cascas de romã (...) (E17 - Escola do campo); quando estávamos com dor de cabeça e dor no corpo e febre, fizemos um chá de eucalipto, alho e limão (E9- Escola metropolitana); ouve o episódio, apenas auxílio juntamente com remédios farmacêuticos (E25 Escola metropolitana); Quando estava com dor no estômago, e minha vó me fez chá de boldo para tomar (E26 - Escola metropolitana).

Refletindo sobre esses relatos apresentados, fundamenta-se toda a visão desses pesquisadores da análise quantitativa apresentada anteriormente, mostrando que as plantas medicinais nesse período da Covid-19 estão sendo manuseadas para atenção primária e o tratamento de sintomas que o vírus pode causar, seja com o uso ou não combinado de um medicamento 
farmacêutico, confirma também que ocorre o uso de plantas medicinais para aumentar a imunidade e prevenção como orienta a cartilha do laboratório de farmacognosia e homeopatia da UFMG em que aponta plantas o fortalecimento do sistema imune como alecrim (Rosmarinus officinalis L.) chá-verde (Camellia sinensis L.) Curcuma (Curcuma longa L.); Erva-Mate (Ilex paraguariensis A.); Equinácea (Echinacea purpurea), entre outras.

Portanto, a partir da relação da pesquisa bibliográfica com a pesquisa empírica, constata-se que não existe ainda uma planta eficaz ao combate ao vírus da Covid-19, contribuindo assim com estudos revelado por Paganoti (2020), que há uma frequência de disseminação de notícias falsas relacionadas à pandemia, dentre elas que envolvem tratamentos e/ou vacinas sem comprovação, como o uso da cloroquina "presidencial" e até mesmo o boldo caseiro.

\section{Considerações finais}

As reflexões deste trabalho demonstraram que a localização e etnosaberes adquiridos pelos estudantes moradores no campo e na região metropolitana não apresentam divergências significativas, considerando a variação de convívio social e cultural. Mostrando em partes que os saberes tradicionais, especificamente plantas medicinais, transcendem espaço, local e tempo.

A pesquisa demonstrou, também, que o conhecimento tradicional das famílias na utilização de remédios caseiros é passado de forma oral e tem sido de uso relevante e resiliente em meio ao enfrentamento dos sintomas causados pelo vírus da Covid-19. E que a utilização das plantas medicinais é ainda disseminada entre as famílias mesmo antes da pandemia para tratamentos de enfermidades. Vale ressaltar a importância da etnobotânica como instrumento de fortalecimento do ser humano com as plantas medicinais e valorização dos etnosaberes locais e a conservação da biodiversidade.

\section{REFERÊNCIAS}

ALHO, Cleber José Rodrigues. Importância da biodiversidade para a saúde humana: uma perspectiva ecológica. Disponível em: https://www.scielo.br/j/ea/a/5ffmTbhgzD3WQMjJPFWx7pK/?format=pdf\&lang =pt. Acesso em: 20 jun. 2021.

BRAGA, Joelma Correia Beralda; SILVA, Luan Ramos da. Consumo de plantas medicinais e fitoterápicos no Brasil: perfil de consumidores e sua relação com a pandemia de Covid-19 / consumption of medicinal plants and herbal medicines in brazil. Brazilian Journal Of Health Review, v. 4, n. 1, p. 3831-3839, 2021. Disponível em:

https://www.brazilianjournals.com/index.php/BJHR/article/view/25393. Acesso em: 20 jun. 2021.

BRANDÃO, M. das Graças Lins; ALMEIDA, Juliana Morais de. Ensinando sobre Plantas Medicinais na Escola. Belo Horizonte, 2011.Disponível em 
http://www.ceplamt.org.br/wp-content/uploads/2014/02/pag_1_pag_181.pdf. Acesso em: 15 de jun. 2021.

CAPRA, Fritjof. Conexão Oculta. Cultrix. São Paulo, 2002.

CASTRO, Marta Rocha de; FIGUEIREDO, Fábio Fonseca. Saberes Tradicionais, Biodiversidade, Práticas Integrativas e Complementares: o uso de plantas medicinais no SUS. DOI:

http://dx.doi.org/10.14393/Hygeia153146605. Hygeia 15 (31): 5-7, Março/2019

Disponível em:

http://www.seer.ufu.br/index.php/hygeia/article/view/46605/26405. Acesso em: 15 jun. 2021.

CARVALHO, Dayanne de Souza et al. Etnobotânica e Uso de Plantas com Potencial Terapêutico em Assentamentos Rurais Brasileiros. 2019.

Disponível em: http://www.revistaea.org/artigo.php?idartigo=3720. Acesso em: 10 jun. 2021.

CAVALCANTI, Isabella Macário Ferro. Plantas Medicinais e Seus Possíveis Benefícios no Enfrentamento da Covid-19. 2020. Disponível em: https://repositorio.ufpe.br/handle/123456789/3816. Acesso em: 10 jun. 2021.

DIEGUES, Antonio Carlos. O Mito Moderno da Natureza Intocada. NUPAUB/USP. 2008.

DIEGUES, Antonio Carlos. Conhecimentos, práticas tradicionais e etnoconservação da natureza. NUPAUB-USP, São Paulo. 2019.

DIEGUES, Antonio Carlos et al. Os Saberes Tradicionais e a Biodiversidade no Brasil. São Paulo: NUPAUB-USP: MMA, São Paulo, 2000

Estado de Minas. Indígenas da Amazônia usam ervas medicinais contra o coronavírus, 2020. Disponível em: https://www.em.com.br/app/noticia/internacional/2020/05/19/interna_interna cional,1148627/indigenas-da-amazonia-usam-ervas-medicinais-contracoronavirus.shtml. Acesso em: 10 jun. 2021.

JESUS, Giovana Karen Barbosa de et al. Plantas Medicinais e Fitoterápicos que Podem ser Usados Durante a Covid-19. Laboratório de Farmacognosia e Homeopatia Farmácia/UFMG. 1 a edição. Proex - UFMG. 2020. Disponível em: https://www.bibliotecaagptea.org.br/agricultura/plantas_medicinais/livros/PLA NTAS\%20MEDICINAIS\%20E\%20FITOTERAPICOS\%20QUE\%20PODEM\%20SER \%20USADAS\%20DURANTE\%20A\%20COVID\%2019.pdf. Acesso em: 10 jun. 2021.

FREIRE, P. Pedagogia da Autonomia: saberes necessários à prática educativa. Paz e Terra. São Paulo, 1996. 
HARARI, Yuval Noah. Uma breve história da humanidade. Porto Alegre, 2020.

GERMANO, Carlos. Pesquisadores da UFPB buscam evidências de remédio natural para Covid-19. 2020. Disponível em: https://www.ufpb.br/ufpb/contents/noticias/pesquisadores-da-ufpb-buscamevidencias-de-remedio-natural-para-covid-19. Acesso em: 20 jun. 2021.

GRANA, Márcia. Consumo de remédios caseiros durante a pandemia de Covid revela necessidade de investimento em cadeia produtiva de plantas medicinais no Amazonas. 2021 Disponível em:

https://ufam.edu.br/noticias-destaque/1522-consumo-de-remedios-caseirosdurante-a-pandemia-de-covid-revela-necessidade-de-investimento-em-cadeiaprodutiva-de-plantas-medicinais-no-amazonas.html. Acesso em: 09 jun. 2021.

KHAN, Suliman et al. Emergence of a Novel Coronavirus, Severe Acute Respiratory Syndrome Coronavirus 2: Biology and Therapeutic Options. Journal of Clinical Microbiology, 2020. Disponível em: https://pubmed.ncbi.nlm.nih.gov/32161092/. Acesso em: 10 jun. 2021.

KFFURI, Carolina Weber. Caderno das Nossas Plantas Medicinais. CNPq, 2011. Disponível em: http://espacoviverzen.com.br/wpcontent/uploads/2017/06/nossas-plantas-medicinais-instrucoes-praticas-epreparacoes.pdf. Acesso em: 11 jun. 2021.

KRENAK, Ailton. O Amanhã não está à venda. Companheira das Letras, 2020

PAGANOTTI, Ivan. Refutação automatizada de notícias falsas na pandemia: interações com o robô Fátima, da agência aos fatos. In: SBPJOR - Associação Brasileira de Pesquisadores em Jornalismo. $\mathbf{1 8}^{\circ}$ Encontro Nacional de Pesquisadores em Jornalismo (SBPJOR). São Paulo, 2020. p. 1-18. Disponível em: http://sbpjor.org.br/congresso/index.php/sbpjor/sbpjor2020/paper/viewFile/27 81/1330. Acesso em: 09 jun. 2021.

PEREIRA, Sílvia Menezes de et al. Utilização da Semente de Linhaça pela População do Município de Campos do Goytacazes-RJ. In: Prática e Pesquisa em Ciências e Tecnologia de Alimentos. (Org). PIOVESAN, Natiéli; SOARES, Juliana Késsia Barbosa Soares; COSTA, Ana Carolina dos Santos Costa. Atena, 2020. Disponível em: https://www.atenaeditora.com.br/postebook/3456. Acesso em: 11 jun. 2021. 
PIRES, Carolina. Pesquisa internacional avalia uso de fitoterápicos no tratamento contra a Covid-19. 2020. Disponível em:

http://www.unbciencia.unb.br/biologicas/60-farmacia/659-pesquisa-avaliauso-de-fitoterapicos-no-tratamento-contra-a-covid-19. Acesso em: 21 jun. 2021.

MAFRA, Rosana Zau; LASMAR, Dimas José; RIVAS, Alexandre Almir. 0 Consumo de Remédios Caseiros Durante a 'Pandemia do Covid-19 e a Evidência da Bioeconomia. Nota técnica. DEA/UFAM. Volume 1. No 7. 2020. Disponível em:

https://edoc.ufam.edu.br/bitstream/123456789/3324/1/NT\%20-\%20v1\%20n7 .pdf. Acesso em: 20 jun. 2021.

NETO, Mercedes et al. Fake news no cenário da pandemia de Covid-19. 2020. DOI: http://dx.doi.org/10.5380/ce.v25i0.72627. Disponível em: https://revistas.ufpr.br/cogitare/article/view/72627. Acesso em: 20 jun. 2021.

SILVA, Robson de Araújo et al. A Utilização da Canela (Cinnamomum), como Suplemento Auxiliar no Tratamento da Diabetes Mellitus Tipo 2. In: II Semana Científica do Agreste Pernambucano. Anais 2020. Volume no 2. GaranhunsPE. Universidade de Pernambuco. Disponível em: https://www.researchgate.net/profile/Maicon-Herverton-Lino-Ferreira-DaSilva-. Acesso em: 22 jun. 2021.

TOMPKINS, Peter; BIRD, Cristopher. A Vida Secreta das Plantas. Expresso Cultura 1986.

Recebido em: 8 de setembro de 2021.

Aceito em: 22 de outubro de 2021. Publicado em: 15 de dezembro de 2021. 